\title{
When Expansionary Fiscal Policy is Contractionary: A Neoklassikal Scenario*
}

\author{
WILLIAM COLEMAN \\ The Research School of Economics, The Australian National University, Canberra, Australia
}

\begin{abstract}
The paper presents a simple theoretical account of how an increase in government purchases may reduce total employment. It is shown that in a 'neoklassikal' model - in which utility maximising consumption choices are combined with a fixed-coefficient technology - an increase in government purchases will reduce the demand for labour at the given wage rate. The reasoning turns on the link between optimising consumption behaviour and employment in the investment sector. An increase in $G$ will (as a matter of arithmetic) make current consumption scarcer relative to future consumption; and thereby reduce the valuation of future consumption in terms of current consumption. As labour is valued according to its contribution to future consumption (through its contribution to capital formation), it follows that an increase in $G$ will reduce the wage at any given volume of employment.
\end{abstract}

\section{Introduction}

The Keynesian doctrine of a positive government spending multiplier has been subject to a manifold critique, both empirically and theoretically. While much of this criticism is underpinned by a confidence in the 'self-correcting' properties of the economy, criticisms of the effectiveness of government spending in stimulating employment have long been pursued within a framework of involuntary unemployment. Some of these critiques invoke the implications of monetary equilibrium; (interest rate crowding out; or, in the open economy, exchange rate

* The author wishes to record the paper's significant debt to the reports of two anonymous referees. The usual disavowals apply. Titles are not subject to copyright, which is all the more reason to acknowledge my evident obligation to Makin (1998).

JEL classifications: E24, E12

Correspondence: William Coleman, The Research School of Economics, The Australian National University, Canberra, ACT 0200, Australia. Email: william.coleman@anu.edu.au crowding out, Fleming (1962) and Mundell (1963)); others invoke capital market equilibrium (see, for example, Makin (2009) and the account of Peden (1984) of the 'Treasury View' of the 1930s); while another influential path of criticism has invoked the 'rational consumer' (the permanent income hypothesis (Friedman, 1957) and Ricardian equivalence (Barro, 1974)). ${ }^{1}$

This paper articulates another avenue of criticism of the government spending multiplier. This path of criticism reaches further than that reached by earlier critiques. For the present paper's critique, contends that government spending will actually be counter productive; it will reduce employment.

\footnotetext{
${ }^{1}$ The critique by way of the rational consumer is not restricted to the efficacy of tax cuts. The permanent income hypothesis suggests a high-marginal propensity to save, and so a low government spending multiplier. Ricardian equivalence treats every increase in $\mathrm{G}$ as if accompanied by an equal increase in $\mathrm{T}$, leaving the impact of $\mathrm{G}$ only a matter of the (small) balanced budget multiplier.
} 
The paper's critique of the government spending multiplier is fashioned in large part out of standard neoclassical materials: perfect foresight, utility maximisation, perfect competition among firms and the absence of any money illusion or rigidities. But it is all done in the context of unemployment, and will allow, as we shall see, for employment to respond positively in some measure to 'demand'.

To the extent that the paper has a novel ingredient that accounts for its results, it is a refusal of a standard neoclassical assumption. For it will be supposed that the demand for labour is not a manifestation of the diminishing marginal productivity of an aggregate production function. Instead of the 'neoclassical' twice differentiable aggregate production function, the model assumes a 'klassikal' fixed coefficient technology operating in two sectors: consumption goods and capital goods. In consequence of this technology, the wage is driven by the valuation, measured in terms of current consumption, of its contribution to future consumption by means of its contribution to capital formation. It is demonstrated that government expenditure reduces that valuation, so that the demand for labour falls. ${ }^{2}$

\section{The Elements of the Model}

This section presents the paper's 'neoklassikal' model; a model that makes all the standard neoclassical assumptions (utility maximisation, perfect foresight, price-taking firms) save one: instead of the neoclassical twice differentiable aggregate production function, the model assumes a 'klassikal' fixed coefficient technology operating in two sectors; consumption goods and capital goods. ${ }^{3}$

\footnotetext{
${ }^{2}$ The neologism 'neoklassikal' is modelled on TW Hutchison's coinage 'Klassikal economics' to denote the conception of Keynes and his followers of classical economics, as distinguished from classical economics itself. (See Hutchison, 1978, p. 123). As 'Klassikal economics' both resembles and (at points) diverges from classical economics, so 'neoklassikal' indicates an approach that both resembles and, in some respects, diverges from the standard neoclassical approach.

${ }^{3}$ It is well understood that 'neoclassical' models can deal with fixed coefficients (see for example Phelps, 1963). It is well known that Leon Walras used fixed coefficients in the first three editions of the Elements of Pure Economics (e.g. Walras, 1874). Nevertheless, 'neoclassical aggregate production function' is synonymous with putty capital and flexible capital/labour ratios.
}

The economy has two outputs; consumption and capital. The production of $\alpha$ units of consumption requires 1 unit of capital and $\beta$ units of labour. There is no possibility of substituting labour for capital in the production of consumption: the isoquants are L shaped, and there is no 'marginal product of labour'. Hence, as long as capital is not a free good, the supply of consumption is determined by the supply of capital

$$
C_{t}=\alpha K_{t} .
$$

The production of one unit of capital requires one unit of labour, and no other input; we might imagine a labourer fashioning with their hands 'a machine'. A unit of capital 'evaporates' at rate $d{ }^{4}$ Thus the quantity of capital in the next period equals $1-d$ of capital in the current period plus the production of capital this period. And because the production of capital this period equals total employment minus employment in the consumption sector, $\beta K$, we have,

$$
K_{t+1}=K_{t}[1-d]+L_{t}-\beta K_{t} .
$$

Consumption is determined by the maximisation of identical homothetic utility functions of the form,

$$
U=C_{t}^{\gamma}+\frac{C_{t+1}^{\gamma}}{1+\delta}+\frac{C_{t+2}^{\gamma}}{[1+\delta]^{2}}+\cdots, \quad \gamma<1
$$

by a given cohort of infinitely lived persons yielding, ${ }^{5}$

$$
\begin{aligned}
\frac{C_{t+1}}{C_{t}} & =\left[\frac{1+\rho_{t}}{1+\delta}\right]^{\sigma} \\
\sigma & \equiv \frac{1}{1-\gamma}
\end{aligned}
$$

where $\rho_{t}=$ rate of profit on investment made in period $t$.

\footnotetext{
${ }^{4}$ Instead being the 'rate of evaporation', $d$ could be equally interpreted as the amount of labour that needs to be spent to 'repair' a machine, without which the machine would have zero productivity. Hence, both $\beta$ and $d$ can be interpreted as operating coefficients. This explains why $\beta$ appears summed with $d$ throughout the model. It also explains why $\beta+d<1$ : if $\beta+d>1$ then building a machine is irrational, as the amount of labour that builds a machine exceeds that amount required to operate it. Its construction, therefore, will necessitate the abandonment of other machines to free up sufficient labour to operate it.

5 'Perfect capital markets' are assumed to exist.
} 
While (4) can be 'read' as a consumption function, it might be more useful here to read it as the basic neoclassical account of the valuation of future consumption in terms of current consumption, $1 /[1+\rho]$. For (4) implies the present value of future consumption, $1 /[1+\rho]$, falls as future consumption becomes plentiful relative to current consumption; that is, as current consumption becomes scarcer relative to future consumption. This proposition - the scarcer current consumption, the less valuable future consumption - is critical to the conclusion of the paper.

The present value of future consumption must also conform to a technological condition: it must equal the ratio of the present consumption cost of producing a machine, $w$, to the future consumption payoff from producing a machine.

$$
\frac{1}{1+\rho_{t}}=\frac{w_{t}}{\alpha-\beta w_{t+1}+[1-d] P_{k, t+1}},
$$

where $P_{k, t}=$ price of a unit of capital in terms of consumption in $t$.

Or, to cast (5) in terms of an expression for the profit rate,

$$
1+\rho_{t}=\frac{\alpha-\beta w_{t+1}+[1-d] P_{k, t+1}}{w_{t}} .
$$

But as long as some capital is produced then the price of capital must match its cost of production,

$$
P_{k, t+1}=w_{t+1},
$$

thus (6) becomes

$$
1+\rho_{t}=\frac{\alpha+[1-\beta-d] w_{t+1}}{w_{t}} .
$$

The model is completed by invoking a wage setting process.

\section{A Full-employment Model}

Suppose, to begin, that the wage rate instantly adjusts to secure full-employment. Then we may write,

$$
L_{t}=\Sigma \text {, }
$$

where $\Sigma$ is the supply of labour. Equations (9) and (2) imply,

$$
K_{t+1}=\Sigma+(1-\beta-d) K_{t} .
$$

Equation (10) constitutes the 'equation of motion' in the capital stock. It is a first-order difference equation with the solution,

$$
K_{t}=\left[K(0)-\frac{\Sigma}{\beta+d}\right][1-\beta-d]^{t}+\frac{\Sigma}{\beta+d} .
$$

Equation (11) states that the profile of capital over time is entirely determined by $K(0), \Sigma, \beta$ and $d$, and is completely independent of preference parameters, $\delta$ and $\sigma$. It also implies that, as long as $K / \Sigma<1 /(\beta+d), K$ will grow over time until a steady state quantity of capital is reached.

$$
K_{\mathrm{SS}}=\frac{\Sigma}{\beta+d} .
$$

Unlike the Ramsey-Solow model, the steady state here is not a matter of an equality between the rate of time preference and the marginal product of capital; there is no marginal product of capital. Rather, the steady state occurs because so much capital has been produced that the entire workforce is absorbed in either operating the existing capital, or in building machines to replace those that wear out. So there is no labour left over to add to the capital stock.

As $C_{t}=\alpha K_{t}$ the path of consumption exactly tracks the quantity of capital,

$$
\frac{C_{t+1}}{C_{t}}=\frac{K_{t+1}}{K_{t}} .
$$

But the growth rate in consumption governs the rate of profit through the equimarginal condition of utility maximisation. So by (13), (10) and (4), we can infer,

$$
\frac{1+\rho_{t}}{1+\delta}=\left[\frac{\Sigma}{K_{t}}+1-\beta-d\right]^{1 / \sigma} .
$$

Evidently (14) determines the rate of profit in any period, by reference to the supply of labour per unit of capital in $t$ and parameters. Equation (14) also implies that as $\Sigma / K$ falls over time, the profit rate will fall over time, until the steady state quantity of capital is reached yielding a steady state rate of profit,

$$
\rho_{\mathrm{ss}}=\delta .
$$

With the profit rate in hand, the expression for the rate of profit rate, (8), can be rewritten to determine the wage rate: 


$$
w_{t}=\frac{\alpha}{1+\rho_{t}}+\frac{[1-\beta-d] w_{t+1}}{1+\rho_{t}} .
$$

Repeated leading and substitution yields,

$$
\begin{aligned}
w_{t}= & \frac{\alpha}{1+\rho_{t}}+\frac{[1-\beta-d] \alpha}{\left[1+\rho_{t}\right]\left[1+\rho_{t+1}\right]} \\
& +\frac{[1-\beta-d]^{2} \alpha}{\left[1+\rho_{t}\right]\left[1+\rho_{t+1}\right]\left[1+\rho_{t+2}\right]}+\cdots .
\end{aligned}
$$

The wage rate equals a sort of 'discounted product' of capital. Given (11) and the expression for the rate of profit in any period $t+i$,

$$
1+\rho_{t+i}=\left[\frac{\Sigma}{K_{t+i}}+1-\beta-d\right]^{1 / \sigma}[1+\delta],
$$

the wage in $t$ can be boiled down to an expression composed solely of parameters and the quantity of capital in $t$. And given the monotonic fall in the rate of profit over time as capital rises over time, the wage must rise over time. It ultimately assumes its own steady state value,

$$
w_{\mathrm{SS}}=\frac{\alpha}{\delta+\beta+d} .
$$

In summary terms, the competitive equilibrium of this neoklassikal model mimics the standard neoclassical model: a falling profit rate profile, a rising wage rate profile and a rising capital per head profile; all ultimately flattening out at steady state values.

\section{An Unemployment Model}

Suppose now that the wage is not set so as to secure full employment, but is arbitrarily given. Employment is now an endogenous variable, dependent on the given wage rate. What is the character of that dependency?

The demand for labour is the sum of "consumption sector labour',

$$
L_{\mathrm{C}, t}=\beta K_{t},
$$

and 'investment sector labour',

$$
L_{\mathrm{I}, t}=K_{t+1}-[1-d] K_{t} .
$$

Consumption sector labour is completely inelastic to the wage rate (at least until the wage is so high that profit on producing consumer goods has shrunk to zero). But investment sector labour is negatively related to the wage rate, as a higher wage means a lower profit rate, and so a lower growth rate in consumption, and so a lower growth rate in capital, and so less investment, and so less investment labour.

Aggregate labour can be derived using an adaption of (8),

$$
\frac{1+\rho_{t}}{1+\delta}=\frac{\alpha+[1-\beta-d] w_{t+1}}{[1+\delta] w_{t}}
$$

and invoking in turn

$$
\left[\frac{1+\rho_{t}}{1+\delta}\right]^{\sigma}=\frac{C_{t+1}}{C_{t}}
$$

and

$$
\frac{C_{t+1}}{C_{t}}=\frac{K_{t+1}}{K_{t}}
$$

and

$$
\frac{K_{t+1}}{K_{t}}=\frac{L_{t}}{K_{t}}+1-\beta-d
$$

yielding:

$$
L_{t}=K_{t}\left[\left[\frac{\alpha+[1-\beta-d] w_{t+1}}{w_{t}[1+\delta]}\right]^{\sigma}-1+\beta+d\right] .
$$

Equation (25) constitutes a labour demand schedule, and is illustrated in Figure 1.

Before turning to analyse the impact of government spending it is worth noting that this employment equation shares with 'Keynesian' models the property that employment increases in response to a rise in the 'marginal efficiency of investment'. Suppose there is an increase in

FIGURE 1

The Demand for Labour in $t$ is a Negative Function of the Wage Rate in $t$

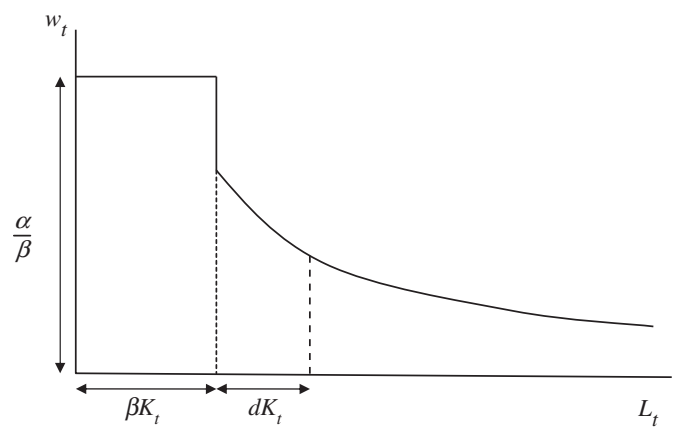


the profitability of machinery on account of machinery in the future requiring less operating labour, and so $\beta_{t+1}<\beta_{t}$.

$$
L_{t}=K_{t}\left[\left[\frac{\alpha+\left[1-\beta_{t+1}-d\right] w_{t+1}}{w_{t}[1+\delta]}\right]^{\sigma}-1+\beta_{t}+d\right] .
$$

Equation (26) implies that for $\beta_{t+1}$ to fall below $\beta_{t}$ is to increase employment at a given wage, reflecting the increase in investment employment on account of the higher ex ante profit rate.

\section{$V$ The Impact of Government Consumption Purchases}

We are now prepared to approach the analysis of the magnitude of the government spending multiplier.

\section{(i) A Fiscal Framework}

A sound analysis of the government spending multiplier calls for a characterisation of the government's spending. We might suppose the government purchases consumption goods, and gives them to the population. This, however, should have no effect on anything: government has simply become the purchasing agent of households, as government purchases have simply substituted for household purchases. The action would be as effectless as simultaneously imposing a tax on households to fund an equal sized tax refund to households.

The characterisation of $G$ that this paper chooses turns on the presumption that the government purchase of consumption goods is intended to increase total demand for consumption goods, and not simply to implement the purchasing plans of households. In consequence of this presumption, we suppose that households will not receive utility from the government purchases of consumption goods. This supposition is in harmony with the classic Keynesian contention that the existence of a (non-zero) government spending multiplier does not require that the government spending itself directly provides any utility. The classic Keynesian contention, recall, is that in times of unemployment it would increase social income for the government to pay people to shift sand (to use Giblin's suggestion of $1932^{6}$ ), or to pay people to fill old holes and then

\footnotetext{
${ }^{6}$ See Giblin's letter to JA Lyons of 19 April 1932, quoted in Coleman et al. (2006, p. 97)
}

dig them up again (to use Keynes' suggestion of $1936^{7}$ ). To pay someone to do such useless tasks is no different from paying someone to make a consumer good, and then not use it. This section therefore proceeds on the assumption that this is what government purchase amounts to, until a relaxation is introduced in the final subsection. Section V turns to the multiplier when $G$ consists of purchasing capital goods.

A reliable analysis of the government spending multiplier also requires a characterisation of the financing of G. It is simplest to assume that a flat tax finances G. But the analysis would be unaltered if we supposed $G$ was financed by a consumption tax, at such a rate as to yield revenues of G. And, if households have foresight of their future tax liabilities, then the analysis would be also unaltered if we supposed $\mathrm{G}$ was financed by government borrowing, as long as the future tax burden is financed by a consumption tax.

\section{(ii) A Temporary Shock to $G$}

Suppose now the government decides to spend $\mathrm{G}$, in real terms, in the current period, but not other periods. Under the fiscal framework assumed in the preceding subsection, the consumption growth rate equation is now altered to,

$$
\frac{C_{t+1}}{C_{t}}=\frac{\alpha K_{t+1}}{\alpha K_{t}-G} .
$$

Thus the employment equation becomes,

$$
\begin{aligned}
L_{t}= & K_{t}\left\{\left[\frac{\alpha+[1-\beta-d] w_{t+1}}{w_{t}[1+\delta]}\right]^{\sigma}-[1-\beta-d]\right\} \\
& -\frac{G}{\alpha}\left[\frac{\alpha+[1-\beta-d] w_{t+1}}{w_{t}[1+\delta]}\right] .
\end{aligned}
$$

The first term in (28) is identical to the right-hand side of (25), and is the level of employment with

\footnotetext{
7 'If the Treasury were to fill old bottles with banknotes, bury them at suitable depths in disused coalmines which are then filled up to the surface with town rubbish, and leave it to private enterprise on well-tried principles of laissez faire to dig the notes up again [...] there need be no more unemployment and, with the help of the repercussions, the real income of the community $[\ldots]$ would probably become a good deal greater than it actually is. It would, indeed, be more sensible to build houses and the like; but if there are political and practical difficulties in the way of this, the above would be better than nothing. (Keynes, 1936, p. 129).
} 
a fixed wage and no fiscal policy. Evidently, then, employment for a given wage is reduced by G. Why? The answer turns on the fall in employment in the investment sector, as employment in the consumption goods sector remains exactly the same as long as profits are positive.

One way of understanding why investment employment falls is to register that a person always faces a choice between consuming themselves or instead paying consumption as wages to someone else to build a machine. To pay someone to build a machine amounts to this person sacrificing their current consumption for the sake of increasing their future consumption. ${ }^{8}$ How much this person is willing to pay someone to build a machine will therefore be dictated by how much the person values future consumption, in terms of current consumption. But an increase in $G$ will cause the value of future consumption, in terms of current consumption, to fall on account of the reduction in current consumption (relative to future consumption) necessitated by the increase in G. Hence, for a given volume of investment the wage rate must fall. Equivalently, for a given wage rate, investment must fall.

A second way of understanding the fall in investment employment is to conceive of the economy as articulated into households (that consume) and firms (that invest). An increase in $\mathrm{G}$ must reduce the current consumption of households. The Euler condition of utility maximisation, (22), implies that as a consequence households will reduce their planned consumption in the following period. That implies a reduction in the required capital stock in the next period, and firms reduce investment accordingly.

\section{(iii) A Future Shock to G}

Suppose now the government decides to spend $\mathrm{G}$, in real terms, in period $t+1$, but not the current period. Under the fiscal framework

\footnotetext{
${ }^{8}$ This trade-off is a private one. Under the assumed technology, a social intertemporal trade-off exists only under a circumstance we are not treating; the circumstance where capital is idle and profits are zero. As long as profits are positive and all capital is employed, society as a whole does not have the opportunity to increase future consumption by reducing current consumption. But decisions are made at the level of the private agent, where the private tradeoff is perfectly real.
}

assumed in the preceding subsection, the consumption growth rate equation is now altered to,

$$
\frac{C_{t+1}}{C_{t}}=\frac{K_{t+1}-G / \alpha}{K_{t}} .
$$

Thus the employment equation becomes,

$$
L_{t}=K_{t}\left\{\left[\frac{\alpha+[1-\beta-d] w_{t+1}}{w_{t}[1+\delta]}\right]^{\sigma}-[1-\beta-d]\right\}+\frac{G}{\alpha} .
$$

Comparing (30) with (25), it is evident that employment for a given wage is increased by G. Equivalently, the wage rate for a given level of employment is increased by future G. Why? Anyone who pays labour to build a machine is effectively sacrificing current consumption for future consumption. How much one is willing to pay that person is dictated by the value of future consumption, in terms of current consumption. The value of future consumption, in terms of current consumption, has been increased on account of the reduction in future consumption. Hence the amount one is willing to pay someone to build a machine has increased.

\section{(iv) A Permanent Shock to G}

Suppose now the government decides to spend $\mathrm{G}$, in real terms, in all periods. The consumption growth rate equation is now altered to,

$$
\frac{C_{t+1}}{C_{t}}=\frac{K_{t+1}-G / \alpha}{K_{t}-G / \alpha}
$$

and so

$$
\begin{aligned}
L_{t}= & \left\{K_{t}\left[\frac{\alpha+[1-\beta-d] w_{t+1}}{w_{t}[1+\delta]}\right]^{\sigma}-[1-\beta-d]\right\} \\
& +\frac{G}{\alpha}\left[1-\left[\frac{\alpha+[1-\beta-d] w_{t+1}}{w_{t}[1+\delta]}\right]^{\sigma}\right] .
\end{aligned}
$$

Evidently, the net effect of current and future G on labour demand is negative as long as investment is positive. Employment for a given wage is reduced by G. This is because a given absolute reduction in $\mathrm{C}$ in both the present and in the future increases the ratio of next period $\mathrm{C}$ to current $\mathrm{C}$, and so reduces the valuation of next period consumption. 
(v) When Government Purchases Provide Some Utility

The conclusion that government spending reduces employment does not require the assumption that government purchases provide zero utility. Suppose that the government purchase of consumption good provides households the utility provided by a fraction, c, of a household purchase of consumption good. So whereas c has thus been assumed zero, we now allow c $>0$. In the case of a temporary G, (27) becomes

$$
\frac{C_{t+1}}{C_{t}}=\frac{\alpha K_{t+1}}{\alpha K_{t}-[1-c] G} .
$$

By the previous train of substitutions we obtain,

$$
\begin{aligned}
L_{t}= & K_{t}\left\{\left[\frac{\alpha+[1-\beta-d] w_{t+1}}{w_{t}[1+\delta]}\right]^{\sigma}-[1-\beta-d]\right\} \\
& -\frac{[1-c] G}{\alpha}\left[\frac{\alpha+[1-\beta-d] w_{t+1}}{w_{t}[1+\delta]}\right] .
\end{aligned}
$$

The impact of $\mathrm{G}$ on $\mathrm{L}$ remains negative, barring the polar case $\mathrm{c}=1$ when the impact is zero. ${ }^{9}$

\section{$V$ The Impact of Government Investment Purchases}

We now turn to analyse the case where tax revenues are used by the government to purchase the capital good. Again, we are interested in assessing an attempt of government to increase aggregate demand by its purchases, rather than anything else. So to prevent this policy amounting also to an extension of government ownership of the capital stock, we suppose the income stream of these machines is used to reduce tax liabilities of households. We can model this as the government giving away the machines to households.

What will be the impact on total employment of this initiative? To the extent that this type of $\mathrm{G}$ shock increases total employment in period $t, K_{t+1} / K_{t}$ must rise. But, critically, the implication of this new characterisation of $G$ has restored the equality of the growth in consumption to the growth in the capital stock, as G no longer wastes capital's output of consumer goods. So it is once more true that:

\footnotetext{
${ }^{9}$ The analysis of this subsection is owed to a referee.
}

$$
\frac{C_{t+1}}{C_{t}}=\frac{K_{t+1}}{K_{t}} .
$$

Thus to the extent that this type of $G$ shock increases total employment in period $t$ it increases $C_{t+1} / C_{t}$, and that will reduce the valuation placed on future consumption. And that will reduce the wage, by the logic explained before. But the wage cannot be reduced, by virtue of our fixed wage assumption. The conclusion is that this type of $G$ shock does not increase total employment at all. Government investment employment exactly displaces an equal amount of private 'investment employment'. In effect, households - seeing the government tax them (say) \$1 million to build machines that they will give back to them - simply let the government do their investment for them to the extent of $\$ 1$ million, and scale back their own investment by $\$ 1$ million. The employment multiplier in this case is not negative, it is zero.

\section{Conclusion}

The paper has added another strand to the variegated theoretical critique of the Keynesian doctrine of a positive government spending multiplier. The paper has advanced a model of the macroeconomy that is simple, has intelligible microfoundations, allows for unemployment, and predicts a positive response in output to an increased profitability of investment; but in which a permanent increase in government consumption purchases will reduce employment.

The intuition is that an increase in $\mathrm{G}$ will (as a matter of arithmetic) make current consumption scarcer relative to future consumption. That will reduce the valuation of future consumption in terms of current consumption. And, as labour in the model is valued according to its contribution to future consumption (through its addition to capital formation), it follows that an increase in $\mathrm{G}$ will reduce the wage at any given volume of labour.

The conclusion is constructed out a number of (inevitably) disputable assumptions, of which the assumption of a fixed coefficient technology is the most critical, and the most salient. But although the technology assumed by the paper is special, it is not in any way 'ill behaved'. On the contrary, Section III has shown that in an equilibrium setting the assumed technology mimics the behaviour of the Ramsey-Solow model with a 'well-behaved' twice differentiable production function. 
The upshot of the paper is to draw attention to the sensitivity of the sign of the government spending multiplier to assumptions about technology. The paper therefore suggests that any case for government spending as a remedy for involuntary unemployment needs to be secured with some 'right' (or facilitating) assumption about technology, in addition to previously recognised need of certain requisite assumptions regarding consumer behaviour and the markets for labour, money and capital.

\section{REFERENCES}

Barro, R.J. (1974), 'Are Government Bonds Net Wealth?', The Journal of Political Economy, 82, 1095-117.

Coleman, W., Cornish, S. and Hagger, A. (2006), Giblin's Platoon: The Trials and Triumph of the Economist in Australian Public Life, ANU E Press, Canberra.

Fleming, J. M. (1962), 'Domestic Financial Policies Under Fixed and Under Floating Exchange Rates', International Monetary Fund Staff Papers, 10, 369-80.
Friedman, M. (1957), A Theory of the Consumption Function, Princeton University Press, New York.

Hutchison, T.W. (1978), On Revolutions and Progress in Economic Knowledge, Cambridge University Press, Cambridge.

Keynes, J.M. (1936), The General Theory of Employment Interest and Money, Macmillan, London.

Makin, A.J. (1998), 'When Contractionary Fiscal Policy Is Expansionary', Agenda: A Journal of Policy Analysis and Reform, 5, 419-26.

Makin, A.J. (2009) 'Fiscal "Stimulus'”: A Loanable Funds Critique', Agenda: A Journal of Policy Analysis and Reform, 16, 22-36.

Mundell, R. A. (1963), 'Capital Mobility and Stabilization Policy Under Fixed and Flexible Exchange Rates', Canadian Journal of Economics and Political Science, 29, 475-85.

Peden, G.C. (1984), 'The "Treasury View' on Public Works and Employment in the Interwar Period', Economic History Review, 37, 167-81.

Phelps, E. S. (1963), 'Substitution, Fixed Proportions, Growth and Distribution', International Economic Review, 4, 265-88.

Walras, L. (1874), Elements d'economie Politique Pure; ou, Theorie de la Richesse Sociale, L.Corbaz, Lausanne. 